\title{
UNA PRINCESA HAFSI DE ORIGEN ESPAÑOL EN TÚNEZ EN TIEMPOS DE IBN-AL-ABBAR ${ }^{\circ} A T F\left({ }^{*}\right)$
}

Por

ABDEL HAKIM EL GAFSI

Las informaciones fragmentarias de que disponemos no nos permiten tener una biografía completa de esta princesa, ya que ignoramos su pasado español como su vida en Túnez.

Sólo con dos afirmaciones, sacadas de la obra de Ibn-Jaldún (1) y de lbnAx-Xammâ, muerto en 1435 (2), y que todos los autores posteriores han repetido, podemos esbozar un inicio de biografía y comprender su importancia en la sociedad tunecina de su tiempo.

${ }^{c}$ Aț (Atf) es, según estas dos fuentes, una antigua esclava cristiana de Galicia, ofrecida por Ibn-Al-Múhtasib, pariente cercano de la familia de ${ }^{\mathrm{C}} \mathrm{Abd}$ AI-Wâhid Ibn-Hfs, al príncipe Abû-Zakariyya, cuando éste no era aún más que gobernador de Idriqiyya, al servicio de los soberanos almohades de Marrakech. Como esposa de éste, le dio varios hijos, que se convirtieron en emires en el nuevo Estado hafsí fundado por su marido Abu-Zakariyya 1. (1228-1249).

Este estado conoció un desarrollo urbano considerable bajo los primeros

(*) Es frecuente encontrar princesas sólo mencionadas por sus nombres personales: Maryam, Hawwâ, ${ }^{\circ} \bar{A}$ ixa, Kutûm, Darb. Ver. S. M. ZBISS, Princes almohado-hafsides, s.d. dactilografiado, pp. 1, 13, 18 20; R. BRUNSCHVIG, La Berbérie orientale sous les Hafsides, París, 1940, II, tableau 1; AZ-ZARKAXI, Tarif, Túnez, 1966, 33.

Hay que notar también nombres femeninos que son títulos o epítetos, en Túnez y por la misma época: Sitat-dar, Sayyida, Sit-al-kull, Āmat-al-ḥaqq, Âmat-al-`azîz, Āmat-ar-rạ̣mân (ver S. M. ZBISS, Les inscriptions de Tunisie, Túnez, 1955, p. 71, nota 129

(1) IBN-JALDUN, Histoire des Berbères et des dynasties musulmanes de l'Afrique septentrionale, trad., de De Slane, Argel, 1854, t. 2, p. 379, citado por R. BRUNSCHVIG, "Quelques remarques historiques sur les médersas de Tunisien, Revue Tunisienne, Túnez, 6, 1931, 265.

(2) IBN-AX-XAMMĀ, Al-adilla; ed. Maamouri, Túnez, 1984, p. 3. 
soberanos de la dinastía: Abû-Zakariyya y su hijo Al-Mustansir (1249-1277), quien se proclamó califa. Este nuevo Estado entabló relaciones muy estrechas con la España cristiana [(tratados de paz y comercio, reclutamiento de una milicia española, etc. (3)], con Al-andalus musulmana y con la comunidad de musulmanes andalusíes refugiados en Túnez, como consecuencia de las conquistas cristianas en la Península Ibérica, a mediados del XIII (4).

Esta princesa participó de forma muy positiva y activa en la acogida de los inmigrantes de Al-Andalus en Túnez. Fue la fundadora de la mezquita y de la escuela (mádrasa) de At-Tawfiqiyya (5), situada en el arrabal meridional de la capital, cerca de la Alcazaba (Al-Qașba), sede político-administrativa de la dinastía, y de los zocos de la Medina de Túnez. El barrio en el que está asentada la mezquita-escuela fundada por Atf era un barrio del Sultán, donde también residían las milicias cristianas con sus familiares y servicios propios. Era también un lugar privilegiado de sufismo y de enseñanza (6).

La mezquita At-Tawfiqiyya sigue siendo una joya de la arquitectura musulmana en territorio tunecino. Se caracteriza por el lugar de su emplazamiento (en las alturas que dominan el lago As-Siŷûmî, de ahí su nombre de «mezquita del viento", Djemaa El-Haoua), así como por su arquitectura (austeridad de decoración y solidez de construcción) heredera de tradiciones andalusíes de época almohade. Desgraciadamente, la escuela o mádrasa de enseñanza superior vinculada a la mezquita no conserva ya su carácter original: hace unos pocos años ha sido transformada para la construcción de un liceo de enseñanza media.

Estas son las noticias y la obra de una princesa muy excepcional, que vino como simple esclava de un país lejano y se convirtió en la "Primera Dama» de una dinastía que tenía que durar más de tres siglos en Túnez, de 1228 a 1530 , fecha de la ocupación española de la capital, por la armada de Carlos $\mathrm{V}$.

(3) Ch. E. DUFourCQ, L'Espagne catalane et le Maghrib aux Xlle et au XIVe siècles, París, 1966, 665 pp.

(4) M. TALBI, "Al-hiŷra al-andalusiyya ilà Ifrikiyya ayyama al-ḥafșiyyîn», Etudes d'mstoire ifriqiyenne, Túnez, 1982, 165-206.

(5) ZAR-RASSA (muerto en 1488), Fihrist, ed. Annabi, Túnez, 1967, 122-123.

AZ-ZARKAXī, Tarîj, ed. Madur, Túnez, 1966, 33.

IBN-ABT-DINĀR, Al-mu'nis, Túnez, 1967, 134.

AS-SARRÂY, Al-hulal, ed. Al-Hila, Túnez, 1970, 1027, 1060 (muerto en 1737).

IBN-ABT-DIYĀF (muerto en 1874), Ithâf, I, 176, 204.

Autores modernos que han tratado de la mezquita y de su fundadora:

BEN BEL, Tarî. Beirut, 1985, 65, 67, 178, 287.

BRUNSCHVIG, R.: "Quelques remarques...n, o.c., p. 265

BRUNSCHVIG, $R$, : La Berbérie..., II, 265, 276, 349, 350

ABDUL-WAHHAB, H. H. , Hahirât at-tûnisiyvât, Túnez, 1966, 105. Este autor reproduce un bonito poema de Muhámmad Xadli Jaznadar sobre la princesa.

ZBISS, S. M.: Monuments de Tunis, Túnez, 1971, 54

ZBISS, S. M.: Inscriptions du Gorjani, Túnez, 1962, V

DAOULATLI, A.: Tunis sous les Hafsides, Túnez, 1976, 165, 294, 295.

BEN-MAMI, B.: Madâris Túnis fî l-aahdain ai-Hfșî wa-t-Turkî, Túnez, 1983, 548.

MAAMOURI, T.: Ŷamica Az-Zituna, Túnez, 1980, 47, 83.

(6) EL GAFSI, A. H.: "Note sur quelques monuments hafsides de Tunis" (en prensa). 


\section{TEXTOS DOCUMENTALES TRADUCIDOS \\ del artículo de Abdel-Hakim EL GAFSI \\ pp. 193-194}

"O illustre, même si votre présence est appelée à disparaître vos oeuvres bénéfiques sont là pour la rappeler a Tunis. Vous fûtes la première à édifier des medersas qui multiplièrent les gratitudes à leurs batisseurs y passèrent tant de générations qui vous prodiguèrent maintes bonnes paroles».

(HH Abdul Wahab, Chahirat at Tunusiyya at, Tunis, Manar, 1966, p 105).

"Nos ancêtres de Séville s'étaient attachés à la cause des almohades, et, quand l'émir Abou-Zékéria, fils d'Abd-el-ouhad le hafside, gouverna l'Ifrikia, un de nos aieux maternels, nommé lbn-el-Mohteceb, lui fit cadeau d'une jeune esclave galicienne dont il fit sa concubine. II eut d'elle plusieurs enfants et elle reçut, pour cette raison, le titre d'ommel khalaif". Ibn Khaldoun, Histoire des berbères et des dynasties musulmanes de l'Afrique septentrionale. Trad. De Slane, Alger, 1854, II, P. 379-380.

"...La mère d'Al Mustansir dénommée Atf avait ordonné la construction de la mosquée At Tawfiq et la médersa du même nom». (Ibn-ax-Xamma, Aladilla, ed. Maamouri, Túnez, 1984, p. 63.). 